\title{
Clinical features of non-tuberculous constrictive pericarditis
}

\author{
H A M I I K R A M, SE A M S O. B A N I M, \\ and ARTHUR R. MAKEY \\ Charing Cross Hospital (Fulham), London W6 8RF
}

\begin{abstract}
Ikram, H., Banim, S. O., and Makey, A. R. (1974). Thorax, 29, 204-208. Clinical features of non-tuberculous constrictive pericarditis. This paper describes the clinical features of five cases of constrictive pericarditis of non-tuberculous aetiology. The findings in this syndrome are compared with those in tuberculous constrictive pericarditis. The non-tuberculous variety had a short history, and absence of ascites and third heart sounds. Pericardial calcification, paradoxical arterial pulse, and the marked ' $y$ ' descent in the venous pulse were absent in contrast to tuberculous constriction. An atrial sound was usual and the chief venous wave was the ' $a$ ' wave.

The difficulty in diagnosing this type of pericardial constriction and its differentiation from 'restrictive' cardiomyopathy is discussed. It is suggested that all currently available diagnostic techniques are liable to failure and, if in doubt, a diagnostic thoracotomy is mandatory.
\end{abstract}

Twelve years ago the majority of cases of constrictive pericarditis were tuberculous in origin (Wood, 1961). Today, with the decline in tuberculosis, constrictive pericarditis has become rarer and is most likely to follow an episode of acute non-specific or acute viral pericarditis. The change in aetiology has been accompanied by a change in clinical presentation which may result in the diagnosis being delayed or missed altogether if classical criteria are too rigidly applied (Table I).

The purpose of this paper is to report our experience with five cases of non-tuberculous

T A B L E I

COMPARISON OF TUBERCULOUS AND NON-TUBERCULOUS CONSTRICTIVE PERICARDITIS

\begin{tabular}{|c|c|c|}
\hline & \multicolumn{2}{|c|}{ Constrictive Pericarditis } \\
\hline & Tuberculous & Non-tuberculous \\
\hline $\begin{array}{l}\text { Duration } \\
\text { Mantoux } \\
\text { Culture for tubercle } \\
\text { bacilli } \\
\text { Pathology of excised } \\
\text { pericardium } \\
\text { Arterial paradox } \\
\text { Ascites } \\
\text { Venous pulse } \\
\text { dominant wave } \\
\text { Third sound } \\
\text { Fourth sound } \\
\text { Pericardial rub } \\
\text { Surgical excision }\end{array}$ & $\begin{array}{l}3 \text { years+ } \\
\text { Positive } \\
\text { Positive early } \\
\text { Negative late } \\
50 \% \text { calcified } \\
\text { Thick, fibrous } \\
\text { Usually present } \\
\text { Usually present } \\
\text { 'y' descent } \\
\text { Usually present } \\
\text { Usually absent } \\
\text { Absent } \\
\text { May be difficult }\end{array}$ & $\begin{array}{l}\text { Less than } 1 \text { year } \\
\text { Negative } \\
\text { Negative } \\
\text { Thin, non-calcified } \\
\text { Patchy } \\
\text { Usually absent } \\
\text { Usually absent } \\
\text { 'a' and ' } x \text { ' descent } \\
\text { Usually absent } \\
\text { Usually present } \\
\text { May be present } \\
\text { Easier and safer }\end{array}$ \\
\hline
\end{tabular}

constrictive pericarditis seen over a six-year $\stackrel{\mathbb{Q}}{\stackrel{2}{2}}$ period. The main features of the syndrome are $\overrightarrow{\overrightarrow{0}}$ presented and are contrasted with those of constrictive pericarditis of tuberculous origin.

\section{PRESENTATION}

There was a history of a recent episode of acute $\stackrel{\sim}{x}$ pericarditis in each case. The chief symptom at the stage of constriction was exertional dyspnoea. Two patients had chest pain in association with a peri- $\delta$ cardial rub. Sinus rhythm and an elevated venous 3 pressure were common to all. The incidence of other 0 features of pericardial disease is listed in Table II.

Viral antibody studies done in two patients during $\frac{}{0}$ the stage of acute pericarditis showed a rising titre to Coxsackie B virus. Mantoux skin tests were negative N and culture of pericardial fluid and tissue for tubercle bacilli was sterile in all.

\section{INVESTIGATIONS}

At the stage of acute pericarditis, four of the five $\stackrel{\odot}{\simeq}$ patients had an enlarged heart shadow on the chest $\stackrel{\odot}{\mathscr{S}}$ radiograph due to a pericardial effusion. As constriction developed the cardiac shadow returned to normal dimensions in all except one, in whom a small effusion $\stackrel{\vec{D}}{\mathbb{D}}$ was still present at operation. Four patients also had $\stackrel{\odot}{\mathcal{Q}}$ pleural effusions. Pericardial calcification was absent.

The electrocardiogram confirmed sinus rythm in all five cases. Four had low voltage QRS complexes and 
T A B L E I I

CLINICAL FEATURES OF NON-TUBERCULOUS CONSTRICTIVE PERICARDITIS

\begin{tabular}{|c|c|c|c|c|c|}
\hline Features & Case 1 & Case 2 & Case 3 & Case 4 & Case 5 \\
\hline $\begin{array}{l}\text { Sex } \\
\text { Age } \\
\text { Aetiology } \\
\text { Duration from acute } \\
\text { pericarditis to } \\
\text { constriction } \\
\text { Symptoms: } \\
\text { Chest pain } \\
\text { Dyspnoea } \\
\text { Fatigue } \\
\text { Signs: } \\
\text { Heart rhythm } \\
\text { Arterial paradox } \\
\text { Raised venous pressure } \\
\text { Oedema } \\
\text { Pericardial rub } \\
\text { Phonocardiography: } \\
\text { 3rd sound } \\
\text { 4th sound } \\
\text { Murmurs. } \\
\text { Venous pulse } \\
\text { Dominant wave } \\
\text { Dominant descent }\end{array}$ & $\begin{array}{l}\text { Male } \\
26 \\
\text { Coxsackie B5 } \\
1 \text { year } \\
\text { Yes } \\
\text { Yes } \\
\text { Yes } \\
\text { SR } \\
\text { No } \\
\text { Yes } \\
\text { Yes } \\
\text { Yes } \\
\text { No } \\
\text { Yes } \\
\text { No } \\
\text { 'a' } \\
\text { 'x' }\end{array}$ & 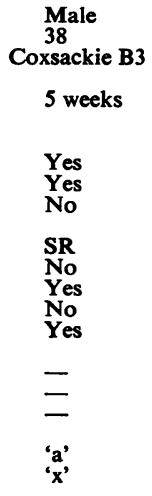 & $\begin{array}{c}\text { Male } \\
57 \\
\text { Non-tuberculous } \\
2 \text { months } \\
\\
\text { No } \\
\text { Yes } \\
\text { No } \\
\text { SR } \\
\text { No } \\
\text { Yes } \\
\text { Yes } \\
\text { No } \\
\text { Yes } \\
\text { No } \\
\text { No } \\
\text { 'a' } \\
\text { 'y' }\end{array}$ & $\begin{array}{l}\text { Female } \\
64 \\
\text { Non-tuberculous } \\
2 \text { months } \\
\\
\text { No } \\
\text { Yes } \\
\text { Yes } \\
\text { SR } \\
\text { No } \\
\text { Yes } \\
\text { Yes } \\
\text { No } \\
\text { No } \\
\text { Yes } \\
\text { No } \\
\text { 'a' } \\
\text { 'x' }\end{array}$ & $\begin{array}{l}\text { Male } \\
23 \\
\text { Non-tuberculous } \\
3 \text { months } \\
\\
\text { No } \\
\text { Yes } \\
\text { No } \\
\text { SR } \\
\text { Yes } \\
\text { Yes } \\
\text { Yes } \\
\text { No } \\
\text { No } \\
\text { Yes } \\
\text { No } \\
\text { 'a' } \\
\text { 'x' }\end{array}$ \\
\hline
\end{tabular}

non-specific repolarization changes prior to pericardiectomy, which returned to normal following surgery. The main value of the ECG was in excluding myocardial infarction.

Right heart catheterization showed that the right atrial pressure was increased in every case, ranging from 16 to $25 \mathrm{~mm}$ of mercury (mean $19 \mathrm{~mm}$ of mercury). The dominant wave was the ' $a$ ' wave (Fig. 1) and the dominant descent was the ' $x$ ' in four and the ' $y$ ' in one. Right ventricular end-diastolic

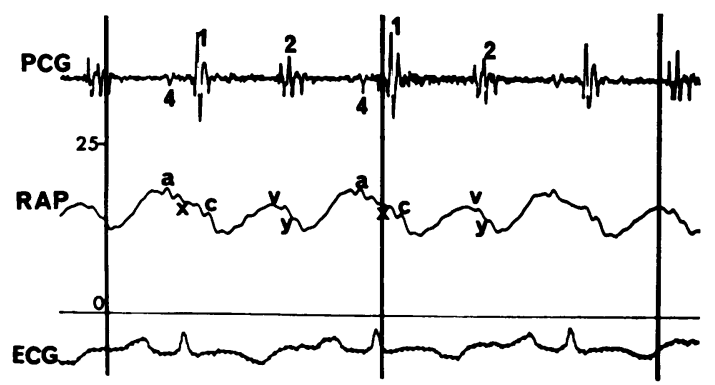

FIG. 1. Right atrial pressure $(R A P)$ and low frequency phonocardiogram $(P G G)$ recorded in the mitral area.

pressure was proportionately increased, ranging from 15 to $24 \mathrm{~mm}$ of mercury. The diastolic portion of the tracing showed the characteristic 'square root' sign (Fig. 2).

We found that injection of contrast medium against the lateral wall of the right atrium (Wood, 1961) was an unsatisfactory method of confirming pericardial thickening. This was probably due to the patchy nature and lesser degree of pericardial thickening encountered in this condition. Angiography was therefore carried out with the catheter positioned in the superior vena cava and $50 \mathrm{ml}$ of Cardio-Conray were injected under $50 \mathrm{lb} / \mathrm{in}^{2}$ pressure. A combined atrial wall and pericardial shadow greater than $2 \mathrm{~mm}$ was considered to be abnormal (Robertson and Arnold, 1965). This technique demonstrated pericardial thickening satisfactorily in every case (Fig. 3). In general, the clinical evidence of constriction was more obvious than the radiological thickening.

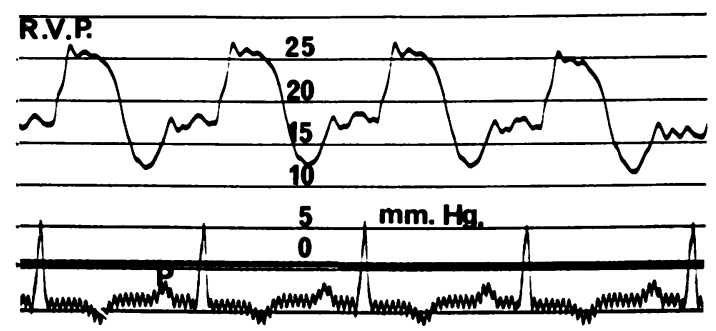

FIG. 2. Right ventricular pressure pulse showing the diastolic plateau or 'square root' sign characteristic of constrictive pericarditis.

\section{OPERATIVE FINDINGS}

The parietal pericardium was markedly thickened (average $8 \mathrm{~mm}$ ) but the visceral pellicle of organizing fibrin was thinner (average $2.6 \mathrm{~mm}$ ) and not uniform in distribution, degree or organization. The visceral layer was thicker over the right side of the heart and atrioventricular groove but the mobility of the left ventricle was always markedly reduced.

A small bloodstained effusion was present in one patient. In places the fibrosis extended into the underlying myocardium.

Following complete ventricular decortication the venous pressure fell by a mean of $12 \mathrm{~cm}$ of water and normal cardiac pulsation returned. 


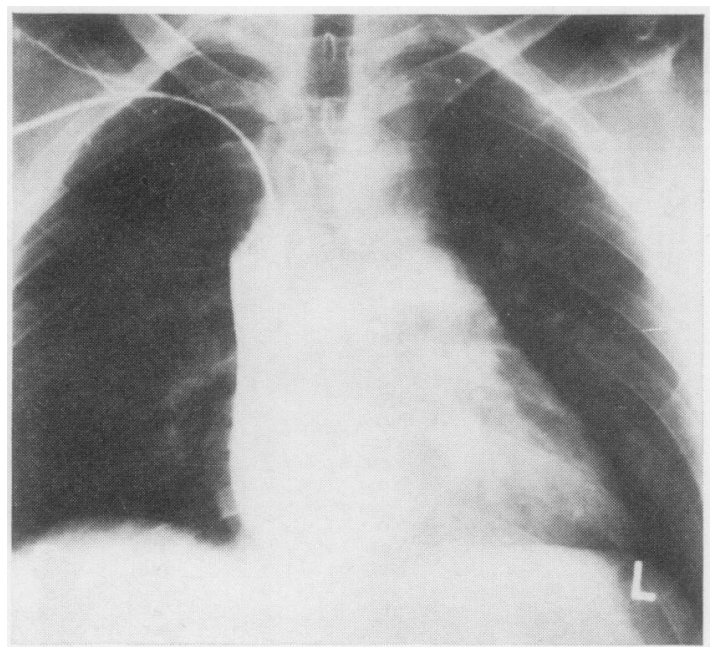

FIG. 3. Angiocardiogram with vena caval injection of contrast medium showing the increased pericardial shadow between the contrast filled right atrium and the lung field.

\section{HISTOLOGY}

The histology of the excised pericardium consisted of thickened cellular fibrous tissue with variable amounts of fibrin and inflammatory granulation tissue. All specimens had perivascular inflammatory infiltrates composed of lymphocytes, plasma cells, histiocytes, and occasional neutrophils. Three had areas of hyaline collagen tissue and of haemorrhage. One had islands of mesothelial cells, another occasional multinucleated giant cells.

It was not possible to distinguish histologically those with raised Coxsackie virus antibody titres and those with non-specific disease. Typical tuberculous features were not found and no calcification was seen.

\section{DISCUSSION}

Several papers have reported the progression of acute idiopathic and acute viral pericarditis to constrictive pericarditis, and this is now widely accepted (Krook, 1954; Rabiner, Specter, Ripstein, and Schlecker, 1954; Connolly and Burchell, 1961; Robertson and Arnold, 1962, 1965; Gibbons, Goldbloom, and Dobell, 1965; Harrold, 1968; Howard and Maier, 1968; Matthews, Cameron and George, 1970).

The difficulty in diagnosing this type of cardiac constriction has been noted by many authors (Robertson and Arnold, 1962; Howard and Maier, 1968; Matthews et al., 1970; McHenry, Ord, Johnston, and Schoener, 1965). The object of our report is to determine features that may be reliable in reaching a diagnosis.
It was possible to obtain a history of a recent bout of pericarditis in each of our cases; indeed, in two there was still a pericardial rub present at the time of constriction. Howard and Maier (1968) have indicated that progression from acute pericarditis to constriction can usually be recognized, if suspected, within one year. The course differs from tuberculous constrictive pericarditis, in which there is usually an indolent progression over many years.

Other symptoms were all non-specific and of no diagnostic assistance.

The jugular venous pressure was markedly elevated in all cases. The most prominent wave in our cases was the ' $a$ ' wave. This is in contrast to usual findings in constrictive pericarditis of tuberculous origin where the ' $y$ ' descent is the most conspicuous feature (Wood, 1961).

A sharp ' $x$ ' descent was the major negative deflection in the venous pulse. This is illustrated in Figure 4.

Hepatosplenomegaly and ascites, which are an integral part of the syndrome of tuberculous pericarditis, were absent in our patients, all of whom had normal liver function tests. This is probably related to the much shorter duration of the disease and hence of hepatic venous congestion.

The third heart sound or 'pericardial knock' has been regarded as a major sign of pericardial constriction (Wood, 1961; Lange, 1967). Its importance is emphasized by Mounsey (1955), who found it in 18 out of 22 cases. However, as Mounsey himself noted, the absence of a third heart sound does not exclude the diagnosis. Gibson (1959) described a syndrome termed 'atypical constrictive pericarditis' in which very severe cardiac constriction was present despite the absence of third heart sounds. In other reports of non-tuberculous pericarditis, it was present in two cases of post- $\frac{\text { ? }}{3}$

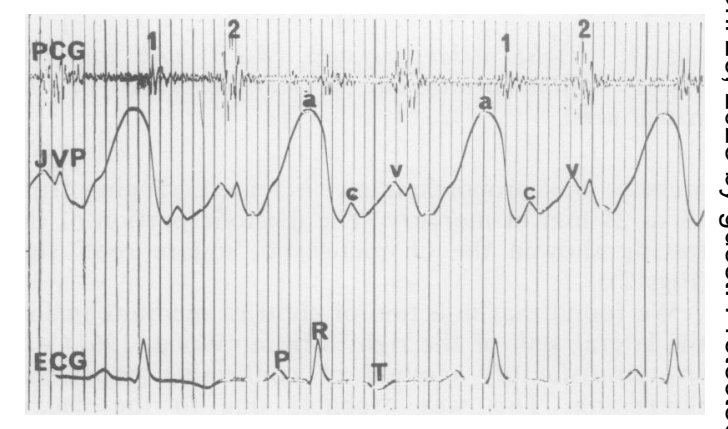

FIG. 4. Jugular venous pulse (JVP) with medium frequency phonocardiogram (PCG). 
Coxsackie constrictive pericarditis (Howard and Maier, 1968; Matthews et al., 1970) but absent in four cases of non-specific constrictive pericarditis (Robertson and Arnold, 1965; Harrold, 1968). The lack of this sound in three of our cases indicates that it may be a particularly unreliable physical sign in constrictive pericarditis of non-tuberculous aetiology. Its absence is probably related to the lack of calcification and the less rigid nature of the pericardial scar in this type of constriction.

Four of our cases had an atrial sound in association with a dominant ' $a$ ' wave on the right atrial pressure pulse. This finding is in contrast to tuberculous constriction. Large amplitude ' $a$ ' waves have also been recorded in non-tuberculous constriction by Matthews et al. (1970) and Robertson and Arnold (1962). The exaggerated atrial wave in these cases probably reflects the atrium assisting in the filling of a non-compliant constricted ventricle. The ability of the atrium to contract with such vigour is possibly because it is not as extensively involved by the fibrotic process, as in tuberculosis. This is evident from both angiographic and operative observations.

The major diagnostic problem in chronic pericardial constriction has always been its differentiation from 'restrictive' cardiomyopathy. In tuberculous constrictive pericarditis much help is provided by the long history, the occurrence of liver dysfunction and ascites, and the frequent presence of a third heart sound and pericardial calcification. Also, the pericardial thickening is gross and hence easily visualized on the angiogram. Percutaneous needle biopsy of this thick pericardium is feasible and leads to a positive histological diagnosis.

In marked contrast, these features are usually absent in non-tuberculous constrictive pericarditis. The shorter history, the absence of ascites and liver failure, the lack of third heart sounds and pericardial calcification, and the presence of large 'a' waves and atrial gallop sounds mimic 'restrictive' cardiomyopathy even more closely. The lesser degree of pericardial thickening and its patchy distribution minimize the help from special investigations. This has also been the experience of several others, and it is recommended that, if the diagnosis remains in doubt after radiological investigations, exploratory thoracotomy is obligatory (Robertson and Arnold, 1965; Matthews et al., 1970).

The severity of the clinical manifestations, despite the short history and lesser degree of pericardial thickening in this condition, has led some authors to attribute the severity of the disease to a complicating 'viral myocarditis' (Howard and Maier, 1968; Matthews et al., 1970). Howard and Maier (1968) further suggest that residual myocarditis may cause postoperative cardiac irritability. For this reason they recommend a more limited pericardial resection on selected cases of viral pericarditis. We have not encountered any serious postoperative arrhythmias and feel that as complete a pericardial clearance as is technically possible should be performed in order to minimize the chances of re-constriction. The postoperative course has been entirely satisfactory in all these cases and residual myocardial failure, as seen in some cases of long-standing tuberculous constrictive pericarditis, has not been encountered so far.

Our experience suggests that the clinical syndrome of constrictive pericarditis needs to be revised. The classical picture of the oedematous, ascitic patient with a long history of ill-health is now rarely seen. Florid pulsus paradoxus, various venous signs, third heart sounds, and pericardial calcification are as likely to be absent as present and make the differentiation from primary myocardial disease very difficult. Indeed, the only consistent features are a raised venous pressure, impalpable apex beat, and muffled heart sounds. Catheter studies indicate a 'restrictive' defect by showing a 'square root' pattern to the ventricular pressure pulse, but this can be pericardial or myocardial in origin. The demonstration of pericardial thickening is crucial in localizing the lesion to the pericardium. This is usually possible by angiocardiography but may require $\mathrm{CO}_{2}$ injection into the pericardial space to be definitely seen. The patchy nature of the thickening may lead to failure of both techniques for the demonstration of pericardial thickening. In such cases, or in a patient with a history of previous pericarditis with a chronically elevated venous pressure, thoracotomy may be required to establish the diagnosis.

The support of the Clinical Research Committee of Charing Cross Hospital is gratefully acknowledged. Our thanks are due to Mr. Bartoli and Miss March for technical help and to Miss Wyvill for typing the manuscript. Hamid Ikram was in receipt of a Governors' Research Fellowship of Charing Cross Hospital.

\section{REFERENCES}

Connolly, D.C. and Burchell, H. B. (1961). Pericarditis: A ten year survey. American Journal of Cardiology, 7, 7.

Gibbons, J. E., Goldbloom, R. B., and Dobell, A. R. C. (1965). Rapidly developing pericardial constriction in childhood following acute non- 
specific pericarditis. American Journal of Cardiology, 15, 863.

Gibson, R. (1959). Atypical constrictive pericarditis (abstract). British Heart Journal, 21, 583.

Harrold, B. P. (1968). Non-tuberculous constrictive pericarditis. British Medical Journal, 1, 290.

Howard, E. J. and Maier, H. C. (1968). Constrictive pericarditis following acute Coxsackie viral pericarditis. American Heart Journal, 75, 247.

Krook, H. (1954). Acute non-specific pericarditis. Study in 24 cases including descriptions of 2 with later development into constrictive pericarditis. Acta Medica Scandinavica, 148, 201.

Lange, R. L. (1967). Treatment of chronic constrictive pericarditis. Modern Treatment (New York), 4, 162.

McHenry, M. M., Ord, J. W., Johnston, R. R., and Shoener, J. A. (1965). Exercise performance and stroke volume changes in two patients with constrictive pericarditis. American Heart Journal, 70, 180.

Matthews, J. D., Cameron, S. J., and George, M. (1970). Constrictive pericarditis following Coxsackie virus infection. Thorax, 25, 624.
Mounsey, P. (1955). The early diastolic sound of constrictive pericarditis. British Heart Journal, $\square$ 17, 143 .

Rabiner, S. F., Specter, L. S., Ripstein, C. B., and Schlecker, A. A. (1954). Chronic constrictive pericarditis as a sequel to acute benign peri- $\varrho$ carditis. New England Journal of Medicine, 251, 0 425.

Robertson, R. and Arnold, C. R. (1962). Pericarditis with particular reference to etiology. Circulation, 26, 525 .

- and - (1965). Acute constrictive pericarditis. Journal of Thoracic and Cardiovascular Surgery, 49, 91.

Wood, P. (1951). Diagnosis of pericardial effusion by ஸ̃ means of cardiac catheterization (abstract). N
British Heart Journal, 13, 574.

(1961). Chronic constrictive pericarditis. 옥 American Journal of Cardiology, 7, 48.

Requests for reprints to: A. R. Makey, M.S., F.R.C.S., $\vec{\bullet}$ Charing Cross Hospital (Fulham), London W6 8RF. I 